\title{
Colon Sessile Serrated Adenoma/Polyp
}

National Cancer Institute

\section{Source}

National Cancer Institute. Colon Sessile Serrated Adenoma/Polyp. NCI Thesaurus. Code C96464.

A polyp that arises from the colon. It is characterized by the presence of serrated glands and the absence of generalized dysplasia. Some authors have suggested that it is a precursor lesion for some colonic adenocarcinomas with microsatellite instability. 